\title{
Administrative Chief Residents - How Are They Chosen and Does It Matter?
}

\author{
Anna Weiss, ${ }^{1,}$ Damini Tandon, ${ }^{2}$ Katherine C. Lee, ${ }^{1}$ Bindu Chandrasekaran, ${ }^{1}$ Nicole Lopez, ${ }^{3}$ Sonia L. \\ Ramamoorthy, ${ }^{1}$ Vanessa Malcarne, ${ }^{4}$ and Sarah L. Blair ${ }^{1}$ \\ ${ }^{1}$ Department of Surgery, University of California, San Diego, USA \\ ${ }^{2}$ School of Medicine, University of California, San Francisco, USA \\ ${ }^{3}$ Department of Surgery, University of North Carolina, Chapel Hill, USA \\ ${ }^{4}$ Department of Psychology, San Diego State University, San Diego, USA \\ "Corresponding author: Anna Weiss, Department of Surgery, University of California, 200 W Arbor Drive, CA 92103, San Diego, USA, E-mail: A3weiss@ucsd.edu
}

Received 2015 November 17; Revised 2015 December 18; Accepted 2016 January 19.

\begin{abstract}
Background: There is no literature on the administrative chief resident (ACR) in surgery or disparities of this leadership position. Objectives: The aim of this study is to examine the rates of perceived female and minority leadership at the resident level.

Patients and Methods: After institutional review board (IRB) approval, a pilot survey was sent to surgical residents and faculty at a single university surgical program. The survey was revised based on small group feedback and a specialist in study design. It was then sent to all US surgical residents and program directors, and analyzed using Survey Monkey.

Results: There was a 10\% resident response rate, 22\% program director, most from a program with $50 \%$ female residents. $71 \%$ report no clear ACR policy, $64 \%$ believe the position appointed. Half report less than $25 \%$ female ACRs, $54 \%$ zero minority ACRs. Program directors reported more female ACRs, but similar lack of selection policy. $54 \%$ believe ACR receives a stipend. $31 \%$ report more than $75 \%$ went into academics.

Conclusions: Although most surgical programs train $50 \%$ female residents, residents perceive that fewer than $25 \%$ ACRs are female. ACRs in the United States are often receiving a stipend and going into academic practice. Programs should keep diversity in mind in appointing ACR.
\end{abstract}

Keywords: Women in Surgery, Leadership, Residency, Surgical Leadership, Women in Academic Medicine

\section{Background}

The underrepresentation of women and minorities fulfilling leadership roles in academia has been well documented. Multiple studies have shown an increasing presence of women and minorities in medical school and academic medicine $(1,2)$. In recent years the number of women graduating from medical school has reached approximately $50 \%(2,3)$. The proportion of women in surgical residency has increased less rapidly, but has reached approximately $30 \%$ - 40\% $(1,4)$. However, in general, the number of women in academic leadership roles is not increasing proportionately as of 2012 only $16 \%$ of faculty is female and only $7 \%$ of full professors are women (5).

Explanations for these discrepancies are multifactorial, but have occasionally been described with "sticky floor" or "glass ceiling" analogies to explain the lack of women in decision-making roles, despite of the presence of qualified women to fulfill them. The "glass ceiling" describes barriers to advancement due to organizational bias for men, by inadvertently excluding women from mentorship or networking (3). The "sticky floor" suggests that the discrepancy is due to women not advancing as quickly, thus having an overrepresentation at the lower leadership levels (6). Some argue that the reason women are not advanced, is that they are not as productive as men; however, this has been disproven by studies controlling for numbers of publications, grants, and teaching awards, and women are still not advanced equally $(2,7)$.

There is evidence that women choose academic careers more often than men; in the years between 1979 and 1997 more women than expected held a faculty position at some point after medical school graduation (2). This would support the "pipeline" the idea that there are more women will be coming into leadership, it will just take time as the higher rates of female medical students, subsequently surgical residents, join the ranks. Unfortunately, this has not been the case $(2,6-10)$. There is also evidence that women tend to be well represented in the program or assistant program director role, but not the chair or division chief position that carries hiring and business responsibilities (11).

Most of these studies have been at the attending level 
$(12,13)$. If the pipeline theory were true for women and minorities, their representation in leadership positions at lower tiers, such as residency where numbers are increasingly proportional, would be expected to be equal.

\section{Objectives}

We hypothesize that the pipeline theory does not explain leadership in academic surgical institutions, and that women and minorities are underrepresented in resident leadership as well as upper tier faculty appointments. Here we aim to examine perceptions regarding diversity of leadership, specifically of the administrative chief position, in general surgical residencies throughout the United States.

\section{Patients and Methods}

The design of this study was an anonymous survey that was sent to surgeons practicing in a training environment in order to assess patterns and perceptions surrounding the position of administrative chief resident. An institutional review board is a governing body for research in the United States. Each university or organization has a review board this board's primary role is to maintain safety in human studies. After obtaining institutional board approval at the university of California San Diego (UCSD IRB number 140188), a 27-question pilot survey was sent via email to surgeons practicing at UCSD at the attending and resident level in the departments of general surgery, plastic surgery, neurosurgery, urology, orthopedic surgery, head and neck surgery.

Questions were developed by the senior authors SLR and SLB, who are general surgery attending surgeons at UCSD. They were modified with the assistance of authors AW and DT. The first survey was tested at UCSD only, and questions were modified using the survey's results and feedback via open forum. The survey was revised with the input from VM who is a psychologist with extensive experience in survey design. The revised survey was 20 questions long (Boxes 1 and 2). After revision, the survey was sent via email to program directors within the United States, who were asked to forward it to their department, as well as take the survey themselves.

The survey was sent twice. It asked respondents to focus on the last 5 years at their respective institutions. The completed surveys were sent anonymously to a website (Survey Monkey). Answers were compiled without any identification of the respondents. Survey Monkey was used to analyze the results. The results of resident surveys were analyzed, and a separate subset analysis of program directors was performed.

\section{Results}

\subsection{Demographics}

The pilot survey was sent to a group of 143 surgeons. A total of $53(37 \%)$ surgeons responded to this pilot survey. 33 (62\%) of respondents identified themselves as general surgeons, $8(15 \%)$ urologists, 6 (11\%) head and neck surgeons (ENT), 4 (8\%) neurosurgeons, 1 (2\%) orthopedic surgeons, and $1(2 \%)$ plastic surgeons. $27(51 \%)$ respondents were faculty and 26 (49\%) were residents.

The final survey was sent to roughly 1000 resident surgeons with 107 respondents, an estimated 10\% response rate, and 235 program directors with 58 respondents (22\% response rate). Table 1 presents the demographics of the final study. Residents were $56 \%$ male, program directors who responded were $63 \%$ male. $2 \%$ of resident respondents had 5 residents in their program, $17 \%$ had 5 - 20 residents, 53\% had 20 - 50 residents, and $28 \%$ had more than 50 residents.

\subsection{Survey Results}

Most (70) respondents reported that $50 \%$ of the residents in their department were women (65\%). 29\% reported their program was $25 \%$ women, and $6 \%$ reported 75\% women, as depicted in Figure 1. 81 (76\%) respondents reported that $25 \%$ of the residents in their department were minorities and $14 \%$ reported that $0 \%$ of the residents in their department were minorities. $16 \%$ of program directors ran programs of more than 50 people; $68 \%$ reported that $50 \%$ of their residents were female, $91 \%$ reported that $25 \%$ of their residents were ethnoracial minorities.

103 respondents reported their department had an ACR (96\%). 75 (71\%) reported that there is no clearly stated policy on how the ACR is chosen. $65 \%$ of program directors (PDs) reported that there was no clear policy on how the ACR is chosen $46 \%$ of the PDs cited appointment, and 33\% reported cycling ACRs. 68 (64\%) of residents believe that the process is appointment, $9 \%$ there is an application process, $15 \%$ nomination by colleague, and $11 \%$ a rotational appointment with each resident having a fixed time as ACR.

Figure 2 represents the percentage of ACRs that have been women and minorities, according to resident perception. $49 \%$ of respondents report less than $25 \%$ of ACRs have been women, and $54 \%$ report less than $25 \%$ of ACRs have been minorities. PDs responded very differently $(\mathrm{P}<0.05)$ - 57\% of PDs report 50\% female ACRs over the past 5 years. Figure 3 represents the percentage of female and minority ACRs as perceived by the program directors. Statistical analysis comparing resident versus PD reported rates for female ACR revealed $P$ values of 0.002 and 0.02 , for survey responses that women are the ACR $25 \%$ or $50 \%$ of the time respectively. 
Box 1. [Part 1] Survey Administered

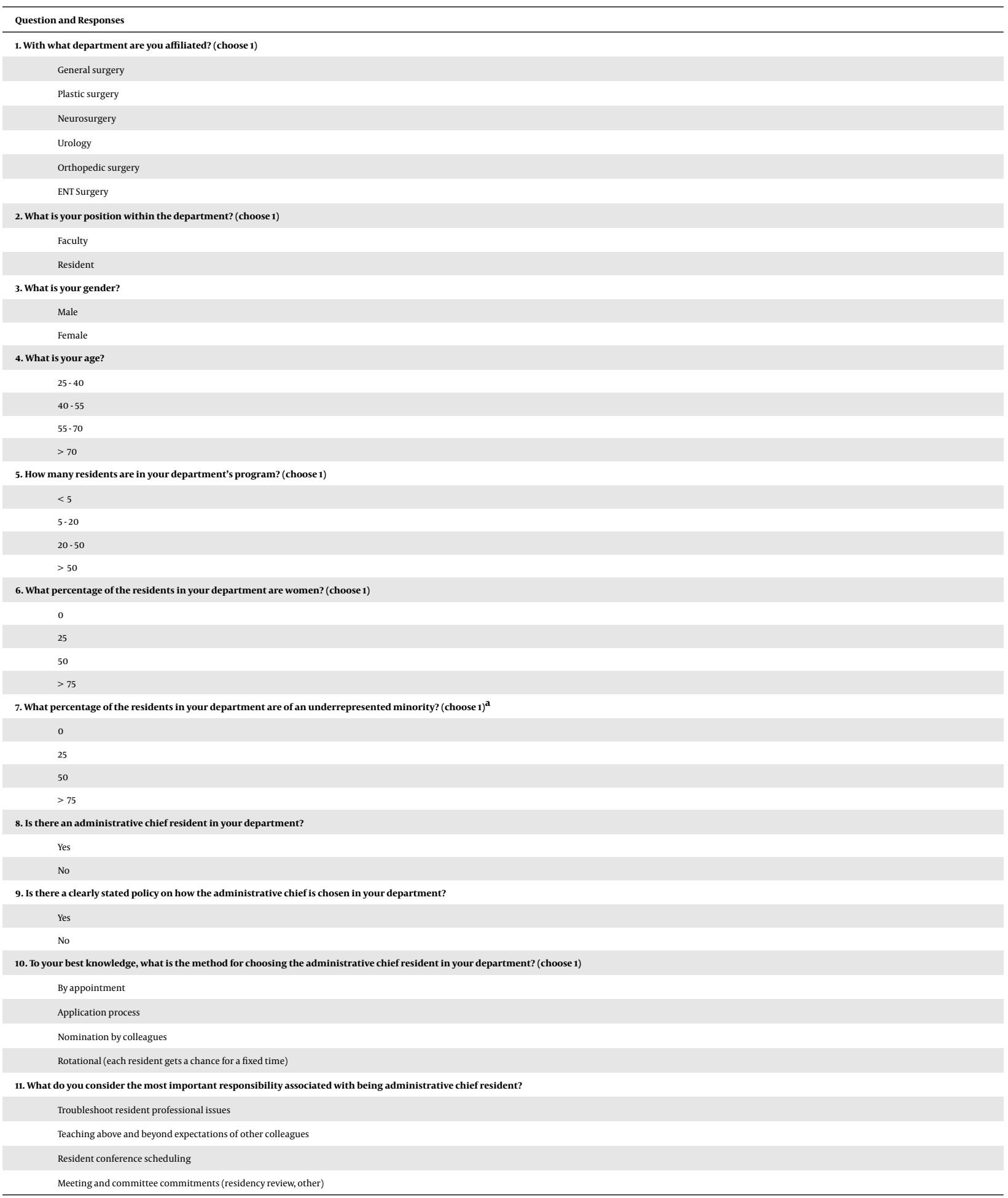

${ }^{\mathrm{a}}$ This includes: African Americans (Black), Hispanic Americans, Native Americans and Alaskan Natives, and Pacific Islanders. 
Box 2. [Part 2] Survey Administered

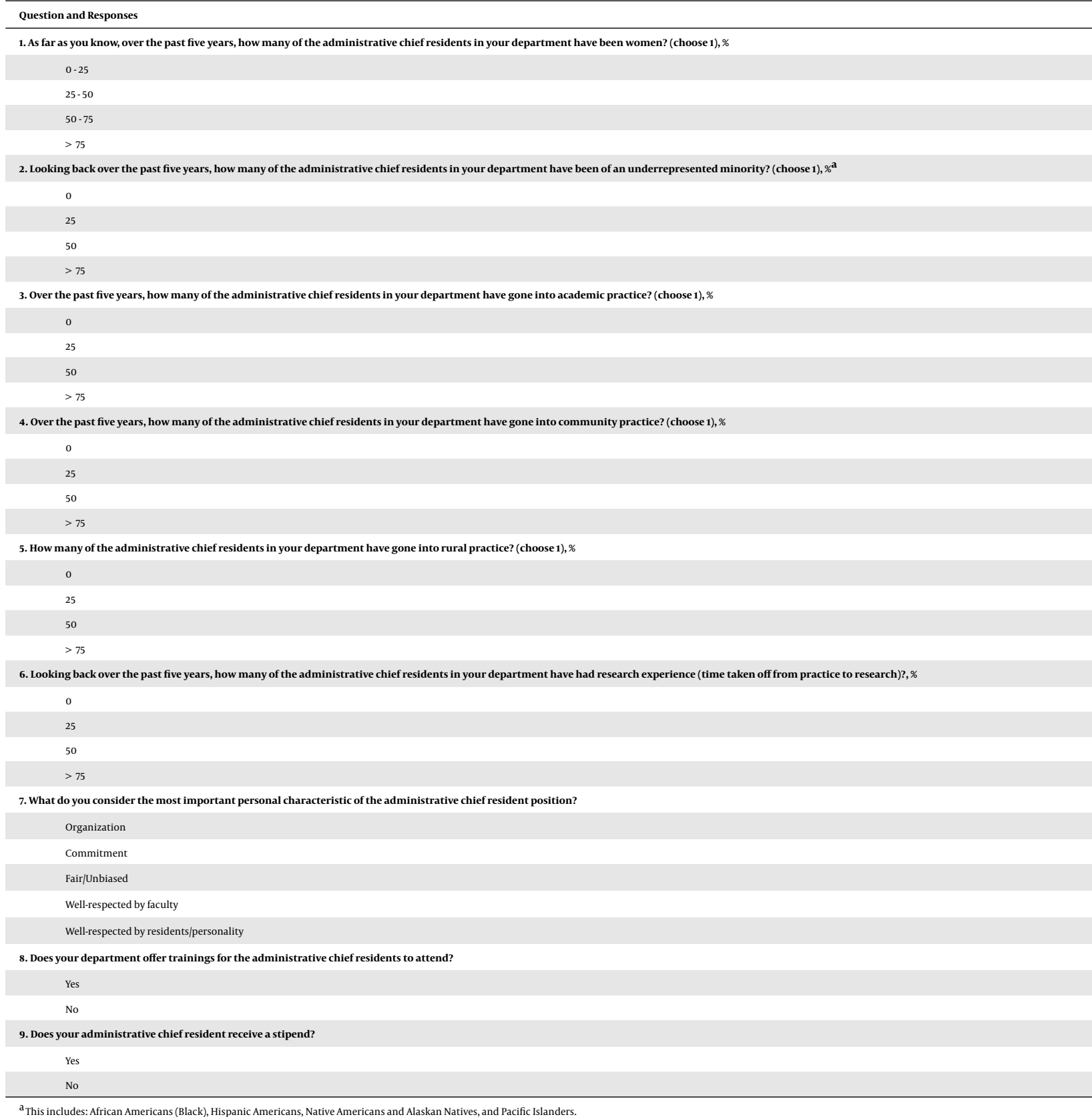

Figure 4 represents the patterns of practice that respondents believe their ACRs have gone into following surgical residency graduation. $16 \%$ of respondents reported that no ACRs went to academics, $19 \%$ reported $25 \%$ went on to academia, $34 \%$ reported that $50 \%$ of their ACRs went on to academia, and $31 \%$ reported that $75 \%$ or more of their ACRs went into academic practice. This trend is the reverse for ACRs going in to community and rural practice. PDs reported that prior ACRs went into academic and community practice at similar rates, even though resident perception is strongly skewed that ACRs go to academic practice. Figure 5 presents the PDs responses on this topic.

Most survey respondents (49\%) believe that designing a call schedule is the most important responsibility of the 
Table 1. Demographics of Resident Respondents

\begin{tabular}{|c|c|}
\hline Variable & Results, No.(\%) \\
\hline \multicolumn{2}{|l|}{ Gender } \\
\hline Male & $60(56)$ \\
\hline Female & $47(44)$ \\
\hline \multicolumn{2}{|l|}{ Program size } \\
\hline 5 & $2(2)$ \\
\hline $5 \cdot 20$ & $18(17)$ \\
\hline $20-50$ & $57(53)$ \\
\hline$>50$ & $30(28)$ \\
\hline \multicolumn{2}{|c|}{ Percentage of residents that are women } \\
\hline 0 & $0(0)$ \\
\hline 25 & $31(29)$ \\
\hline 50 & $70(65)$ \\
\hline 75 & $6(6)$ \\
\hline \multicolumn{2}{|c|}{ Percentage of residents that are minority } \\
\hline 0 & $15(14)$ \\
\hline 25 & $81(76)$ \\
\hline 50 & $9(8)$ \\
\hline 75 & $2(2)$ \\
\hline
\end{tabular}

A

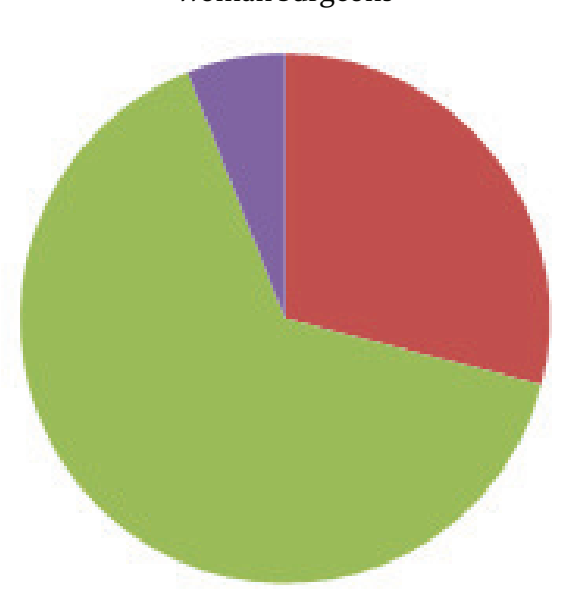

B

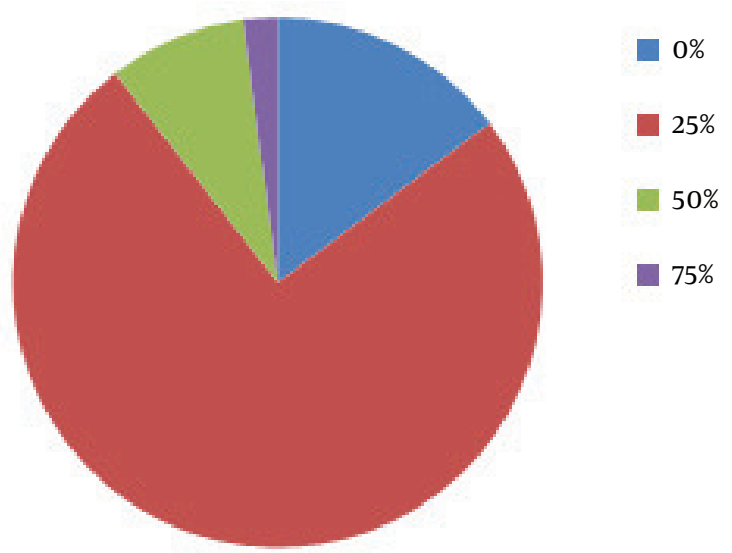

Figure 1. The demographics of Survey Respondents' Surgery Residency Programs, Through Self-Reporting

administrative chief. $30 \%$ believe troubleshooting resident issues most important, $12 \%$ find teaching above their peers, $3 \%$ think resident conference scheduling, and $7 \%$ believe meetings and committees such as residency review to be the most important. Program directors felt that designing a call schedule was the most important responsibility. $28 \%$ of resident respondents feel that the most important personal characteristic of the ACR is being well respected by their peers. Next were $24 \%$ felt that being fair/unbiased, $23 \%$ being organized, $14 \%$ being committed to the job, and $11 \%$ being well respected by faculty were the most impor- tant personal characteristics. Program directors felt that being organized was the most important trait of an ACR.

Only 29\% (30/107) respondents reported that their administrative chief resident is offered departmental training. 54\% report that the administrative chief resident receives a stipend. 54\% of PDs also reported the ACR received a stipend, but still 56\% report there is no formal training. 
A

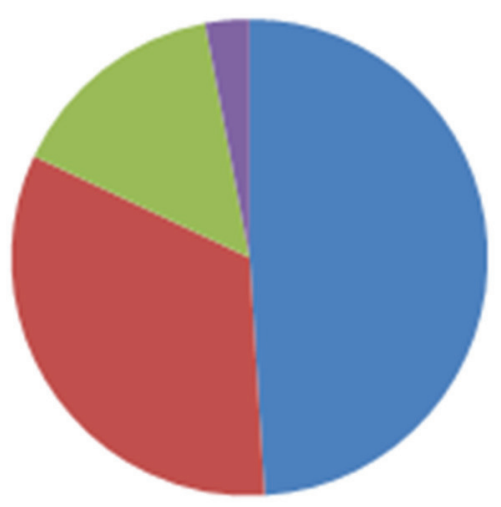

B

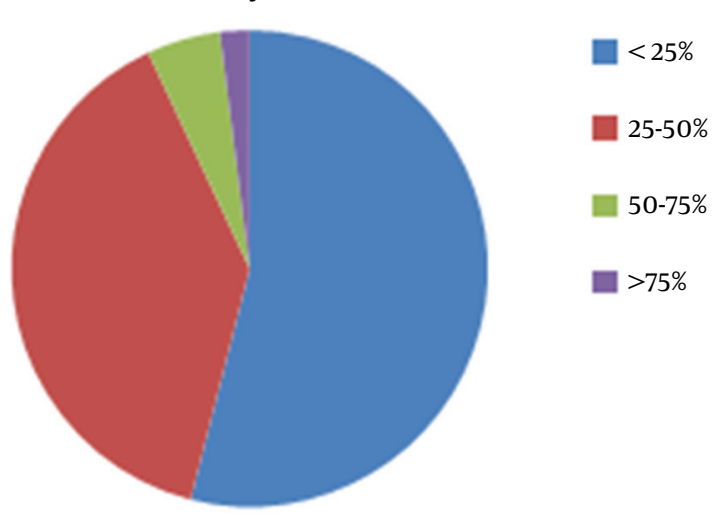

Figure 2. Resident Perception of the Percentage of Administrative Chief Residents That Have Been Women and Minorities

A

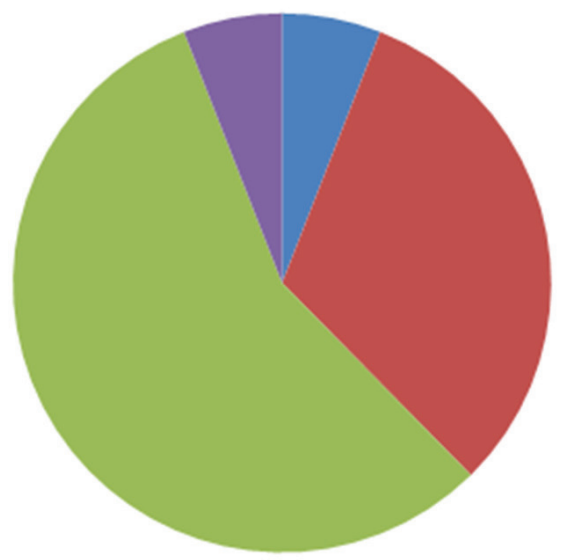

$<25 \%$

$25-50 \%$

$50-75 \%$

$>75 \%$

Figure 3. Program Director Perception of the Percentage of Administrative Chief Residents That Have Been Women and Minorities

\section{Discussion}

The current study demonstrates a similar trend of underrepresentation of women and minorities in surgical resident leadership positions, as is well documented for attending surgeons. While the majority (65\%) of resident respondents report that $50 \%$ of the surgical residents are women, half (49\%) indicated that less than one-quarter of their ACRs have been women. There is a similar finding for minority surgery residents. Interestingly, program directors report 50\% women residents as well as 50\% women ACRs. This implies that residents perceive a disparity at this level as well, and the results challenge the pipeline theory. Given greater gender balance in residency, the pipeline
B

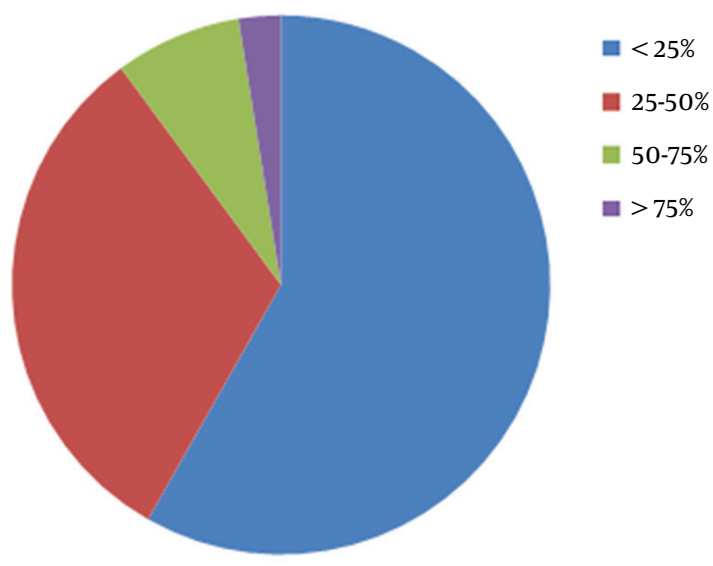

$<25 \%$

0-75\% 


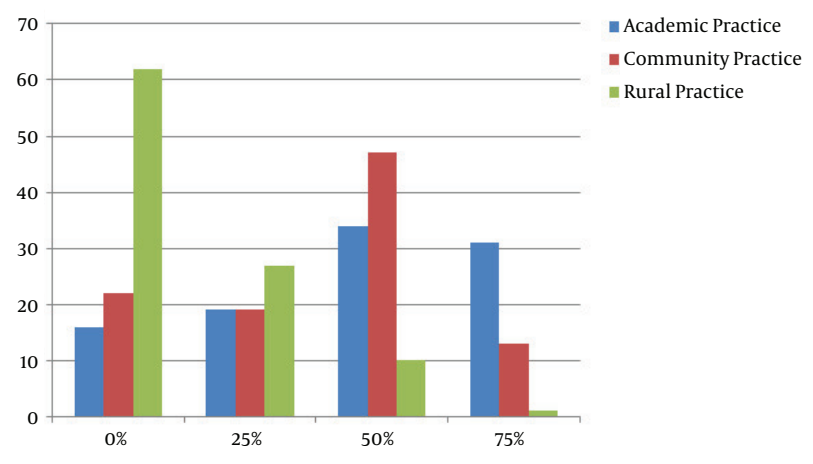

Figure 4. Practice Patterns of Past Administrative Chief Residents, as Perceived by Survey Respondents

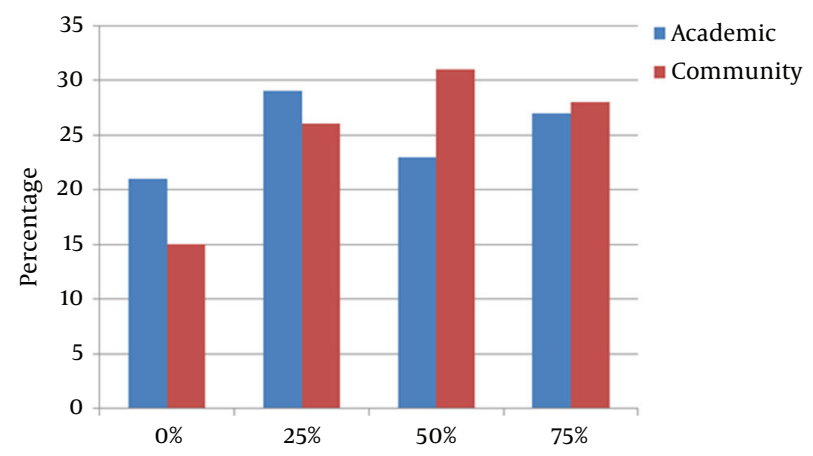

Figure 5. Practice Patterns of Past Administrative Chief Residents, as Reported by Program Directors

structure of surgery is hierarchical (1). This hierarchical structure has been cited as a possible barrier to academic advancement of women in medicine; (16) high-level academic leaders atop the hierarchy often have an indeterminate tenure, leading to advancement schemas that lack transparency (1). Such traditionally hierarchical appointment systems may, in part, explain the bottleneck effect that hinders advancement of women (16) since biases and discrimination have an opportunity to play a greater role when transparency is lacking (14). While the position of ACR is typically only one year, a similar lack of transparency $71 \%$ of resident participants and $46 \%$ of program directors indicating that ACR is determined by appointment may perpetuate a lack of female leadership in this position.

This missed opportunity early in a woman's career may have lasting implications. ACR is a position in which the resident often works closely with the program director and chairman as a resident liaison. Being appointed ACR is commonly regarded as an excellent leadership opportunity and many suggest that ACRs go on to hold impor- tant administrative positions in their careers (17). Alpert et al. report, as compared with non-chief residents, former chief residents surveyed were more likely to consider themselves leaders, have received honors and held more leadership positions. Predictors of leadership were chief resident status, male gender, and honors received (17). Similarly, in a study of attendings, having been a chief resident was associated with being named an excellent role model (18). These studies imply that serving as an ACR may be an indicator or stepping stone to future academic leadership. The results of the current study indicate a similar possibility the majority of respondents reporting that the ACR receives a stipend and goes into academic practice. Whether the ACR career path is actually more academic than other residents (not so according to program directors), residents certainly believe that ACRs are more academically inclined.

A potential limitation of this study and survey studies in general is a combination of sampling and response bias. Respondents that feel there is an injustice that needs addressed may be more inclined to take time to answer the survey, thus skewing the results. This is a possible explanation for the discrepancy between responses of residents and program directors. Another potential bias is questioner reliability, the questions could be leading in nature, although this was controlled for by using an outside expert in study design. Further potential bias exists because residents chosen for the ACR position likely exhibit personal attributes that make them more inclined to academic success, which may overestimate the implied importance of ACR appointment to attaining a leadership position. Another limitation is the low response rate - accountability is difficult to achieve when reaching residents nationally via email. There is no perceived benefit to spend time filling out a survey amidst a busy surgical resident schedule. Furthermore, the actual response rate cannot be accurately calculated because it is unknown how many program directors or residency coordinators actually forwarded the study email, or how many residents actually read the email. An alternative method of delivery is a survey following the American board of surgery in-training exam, this is a captive audience, but is very tightly regulated. Last, the low response rate and sampling bias may explain the resident-program director discrepancy as well. If one program had 30 respondents, this could skew the results. It is possible that the program director responses are more accurate; however there is still an important message in this. The perception that residents hold regarding the resident leadership ACR position is noteworthy. 


\subsection{Conclusions}

Although most surgical programs in the country train $50 \%$ female residents, most residents report less than $25 \%$ female ACRs over the last 5 years. A similar trend exists for minorities. ACRs in the United States are often receiving a stipend and going into academic practice. ACR is a position that most feel commands respect, and grants potential monetary and career advantages; programs should keep diversity in mind in appointing the administrative chief resident.

\section{Acknowledgments}

There are no acknowledgements. This project was presented at Association of Academic Surgeons-Society of University Surgeons Academic Clinical Congress in February 2015.

\section{Footnotes}

Authors' Contribution: Anna Weiss designed the survey and wrote the manuscript. Damini Tandon designed the survey. Katherine C. Lee provided critical revisions to the manuscript. Bindu Chandrasekaran designed the survey. Nicole Lopez designed the survey and provided critical revisions to the manuscript. Sonia L. Ramamoorthy designed the survey and provided critical revisions to the manuscript, and Sarah L. Blair designed the survey and provided critical revisions to the manuscript. Vanessa Malcarne is a psycologist with extensive experience in survey design who helped revise the survey.

Financial Disclosure: There are no relevant financial disclosures to report for any authors regarding the manscruipt.

Funding/Support: There is no funding source for this research.

\section{References}

1. Sexton KW, Hocking KM, Wise E, Osgood MJ, Cheung-Flynn J, Komalavilas P, et al. Women in academic surgery: the pipeline is busted. Surg Educ. 2012;69(1):84-90. doi: 10.1016/j.jsurg.2011.07.008. [PubMed: 22208838].
2. Nonnemaker L. Women physicians in academic medicine: new in sights from cohort studies. $N$ Engl J Med. 2000;342(6):399-405. doi: 10.1056/NEJM200002103420606. [PubMed: 10666431].

3. Zhuge Y, Kaufman J, Simeone DM, Chen H, Velazquez OC. Is there still a glass ceiling for women in academic surgery?. Ann Surg. 2011;253(4):637-43. doi: 10.1097/SLA.0b013e3182111120. [PubMed: 21475000].

4. Davis EC, Risucci DA, Blair PG, Sachdeva AK. Women in surgery residency programs: evolving trends from a national perspective. $J$ Am Coll Surg. 2011;212(3):320-6. doi: 10.1016/j.jamcollsurg.2010.11.008. [PubMed: 21247778].

5. Jolliff L LJ, Coakley E, Sloane RA. Women in U.S. academic medicine and science: Statistics and benchmarking report. Washington, D.C: Association of American Medical College; 2012.

6. Tesch BJ, Wood HM, Helwig AL, Nattinger AB. Promotion of women physicians in academic medicine. Glass ceiling or sticky floor?.JAMA. 1995;273(13):1022-5. [PubMed: 7897785].

7. Wright AL, Schwindt LA, Bassford TL, Reyna VF, Shisslak CM, St Germain PA, et al. Gender differences in academic advancement: patterns, causes, and potential solutions in one US College of Medicine. Acad Med. 2003;78(5):500-8. [PubMed:12742788].

8. Hoover EL. Mentoring women in academic surgery: overcoming institutional barriers to success. J Natl Med Assoc. 2006;98(9):1542-5. [PubMed: 17019926].

9. Freischlag JA. Women surgeons-still in a male-dominated world. Yale J Biol Med. 2008;81(4):203-4. [PubMed: 19099052].

10. Buyske J. Women in surgery: the same, yet different. Arch Surg. 2005;140(3):241-4. doi: 10.1001/archsurg.140.3.241. [PubMed: 15781785].

11. Weiss A, Lee KC, Tapia V, Chang D, Freischlag J, Blair SL, et al. Equity in surgical leadership for women: more work to do. Am J Surg. 2014;208(3):494-8. doi: 10.1016/j.amjsurg.2013.11.005. [PubMed: 24933664].

12. Jonasson O. Women as leaders in organized surgery and surgical education. Has the time come?. Arch Surg. 1993;128(6):618-21. [PubMed: 8503762].

13. Jonasson O. Leaders in American surgery: where are the women?. Surgery. 2002;131(6):672-5. [PubMed:12075183].

14. Reskin BF. Getting it right: Sex and race inequality in work organizations. Annu Rev Sociol. 2000;26:707-9.

15. Kanter RM. The impact of hierarchical structures on the work behavior of women and men. Soc Probl. 1976;23(4):415-30.

16. Conrad P, Carr P, Knight S, Renfrew MR, Dunn MB, Pololi L. Hierarchy as a barrier to advancement for women in academic medicine. JWomens Health (Larchmt). 2010;19(4):799-805. doi: 10.1089/jwh.2009.1591. [PubMed: 20141385].

17. Alpert JJ, Levenson SM, Osman CJ, James S. Does being a chief resident predict leadership in pediatric careers?. Pediatrics. 2000;105(4 Pt 2):984-8. [PubMed:10742360].

18. Wright SM, Kern DE, Kolodner K, Howard DM, Brancati FL. Attributes of excellent attending-physician role models. $N$ Engl J Med. 1998;339(27):1986-93. doi: 10.1056/NEJM199812313392706. [PubMed: 9869671]. 